\title{
Human intestinal $M$ cells exhibit enterocyte-like intermediate filaments
}

\author{
T Kucharzik, N Lügering, K W Schmid, M A Schmidt, R Stoll, W Domschke
}

\begin{abstract}
Background-The derivation and ultrastructural composition of $M$ cells covering the lymphoid follicles of Peyer's patches is still unknown. Results from different animal models have shown that there are species specific differences in the composition of intermediate filaments between $M$ cells and neighbouring enterocytes. Little is known, however, about intermediate filaments of human $M$ cells. Aims-To compare components of the cytoskeleton of human $M$ cells with those of adjacent absorptive enterocytes.

Methods-The expression and localisation of different cytokeratins, vimentin, and desmin in $M$ cells was determined on follicle associated epithelia of human appendix using immunohistochemistry and immunogold electron microscopy.

Results-Cytokeratins specific for human intestinal epithelial cells such as cytokeratins $8,18,19$, and 20 were expressed in both absorptive enterocytes and $M$ cells with no differences in intensity and cellular distribution between both cell types. Vimentin and desmin, tissue specific markers of either mesenchymal or myogenic cells, as well as other cytokeratins were not detectable in enterocytes or $M$ cells.

Conclusion-This is the first study on the structure of intermediate filaments in human intestinal $M$ cells. Our results show that in contrast to several animal models, human $M$ cells apparently do not differ from adjacent enterocytes in the composition of their intermediate filament cytoskeleton. The presence of enterocyte like cytokeratins and the absence of other cytokeratins as well as of vimentin and desmin supports the hypothesis of an epithelial origin of human intestinal $M$ cells and suggests that $M$ cells may derive from differentiated enterocytes. (Gut 1998;42:54-62)
\end{abstract}

Keywords: human intestinal M cells; appendix; cytokeratin; intermediate filaments; follicle associated epithelium

$\mathrm{M}$ cells are known as specialised antigen sampling cells that are interspersed between epithelial cells of the follicle associated epithelia (FAE) of the gastrointestinal and respiratory tracts. ${ }^{1-7}$ They differ morphologically and enzymatically from the adjacent enterocytes, show preferential affinity for certain microorganisms, ${ }^{8-11}$ and take up and transport antigens..$^{5612}$ As $M$ cells have a high capacity for transcytosis of a wide range of microorganisms and macromolecules, they are believed to act as an antigen sampling system. ${ }^{3}{ }^{4} \mathrm{M}$ cells can be characterised electron microscopically by their characteristic morphology, notably their atypical microvilli and the presence of an invagination of the basolateral membrane harbouring leucocytes. ${ }^{4}$ Since the first report on $\mathrm{M}$ cells in the human ileum ${ }^{1}$ and appendix, ${ }^{2}$ numerous studies have been done to elucidate their morphology and to investigate functional aspects of $M$ cells in different animal species (for review see $\operatorname{Trier}^{7}$ ). Little is known, however, about the function and morphology of $M$ cells in humans. Concerning their morphology, human $M$ cells reveal an anastomosing, short, ridgelike network of folds and occasionally short microvilli in strong contrast to the regular appearance of microvilli of adjacent absorptive cells. ${ }^{13}$

Different enzymatic markers for the recognition of $M$ cells have been established, such as alkaline phosphatase in the brush border. ${ }^{14}$ Other investigators have determined immunohistochemical markers for $M$ cells, but all are restricted to single animal species. Gebert et al have shown that cytokeratin $18(\mathrm{CK}-18)$ is a sensitive marker for porcine $\mathrm{M}$ cells ${ }^{15}$ while vimentin is selectively expressed in rabbit $M$ cells. ${ }^{16} \mathrm{M}$ cells in rats are detected by monoclonal antibodies (clone 4.1.18) raised against cytokeratin $8 .^{17}$ Allthough all markers identified thus far seem to be species specific, these studies did show that $M$ cells of various animals differ in their composition of cytoskeleton proteins from adjacent enterocytes. These observations suggest that different intermediate filaments serve variable function $\mathrm{s}^{15}{ }^{16}$ which could explain the different properties of $M$ cells compared with enterocytes.

Within the system of intermediate filaments, the subgroup of cytokeratins might serve as a system of especially potent differentiation markers, because the diverse patterns of cytokeratin polypeptides are correlated with different pathways of epithelial differentiation. ${ }^{18}$ To our knowledge, no data are available concerning the components of the cytoskeleton of human $\mathrm{M}$ cells. There is controversy as to whether $M$ cells are of epithelial-intestinal or mesenchymal origin. Whether $M$ cells derive from intestinal crypt cells or from fully differentiated enterocytes and whether this stage in differentiation is induced by lymphoid tissues is also not known.

As the properties of specialised $M$ cells in the FAE are different from those of common enterocytes, the aim of our study was to investigate
Accepted for publication 16 July 1997 
Table 1 Antibodies

\begin{tabular}{llll}
\hline Antibody & Clone & Supplier & Dilution \\
\hline Anticytokeratin 1/2, 10/11 & AE2 & Progen & $1 / 50$ \\
Anticytokeratin 3 & AE5 & Progen & $1 / 50$ \\
Anticytokeratin 4 & 215B8 & Boehringer & $1 / 200$ \\
Anticytokeratin 5/6 & D5/16B4 & Boehringer & $1 / 1000$ \\
Anticytokeratin 6 & Ks 6KA12 & Progen & $5 \mu \mathrm{ml}$ \\
Anticytokeratin 7 & Ks 7.18 & Progen & $5 \mu \mathrm{g} / \mathrm{ml}$ \\
Anticytokeratin 8 & 4.1 .18 & Boehringer & $1 / 40$ \\
& Ks 8.7 & Progen & $5 \mu \mathrm{g} / \mathrm{ml}$ \\
Anticytokeratin 10/11, 1/2 & Ks 8.10 & Progen & $5 \mu \mathrm{g} /$ \\
Anticytokeratin 13 & K8.60 & Progen & $1 / 50$ \\
Anticytokeratin 14 & KS13.1 & Progen & $1 / 20$ \\
Anticytokeratin 16 & LL002 & Medac & $1 / 20$ \\
Anticytokeratin 17 & LL025 & Medac & $1 / 40$ \\
Anticytokeratin 18 & Ks 17.E3 & Progen & $5 \mu \mathrm{g} / \mathrm{ml}$ \\
& CY-90 & Sigma & IH 1/800 \\
Anticytokeratin 19 & & & EM 1/1000 \\
Anticytokeratin 20 & Ks 18.04 & Progen & $5 \mu \mathrm{g} / \mathrm{ml}$ \\
& A53-B/A2 & Sigma & IH 1/10 \\
Anticytokeratin 8 +18 & Ks 20.10 & Progen & EM $1 / 2$ \\
Antivimentin & Ks 20.8 & Progen & $1 / 20$ \\
Antidesmin & CAM 5.2 & Becton-Dickinson & $5 \mu \mathrm{g} / \mathrm{ml}$ \\
& V9 & Immunotech & $1 / 2$ \\
\hline
\end{tabular}

IH, immunohistochemistry; EM, immunoelectron microscopy.

whether this functional difference might be reflected in an unusual range of cytoskeletal proteins. We therefore examined different components of the cytoskeleton in $\mathrm{M}$ cells of the human appendix in comparison with adjacent absorptive enterocytes by immunohistochemistry and immunogold electron microscopy. We determined the expression of tissue specific cytoskeletal proteins such as different cytokeratins, vimentin, an intermediate filament protein present in mesenchymal cells, and desmin, a marker for myogenic cells in human intestinal $M$ cells.

\section{Materials and methods}

TISSUE

To examine human intestinal $\mathrm{M}$ cells, we used surgical specimens of human appendix. Appendices were obtained from 13 patients (four

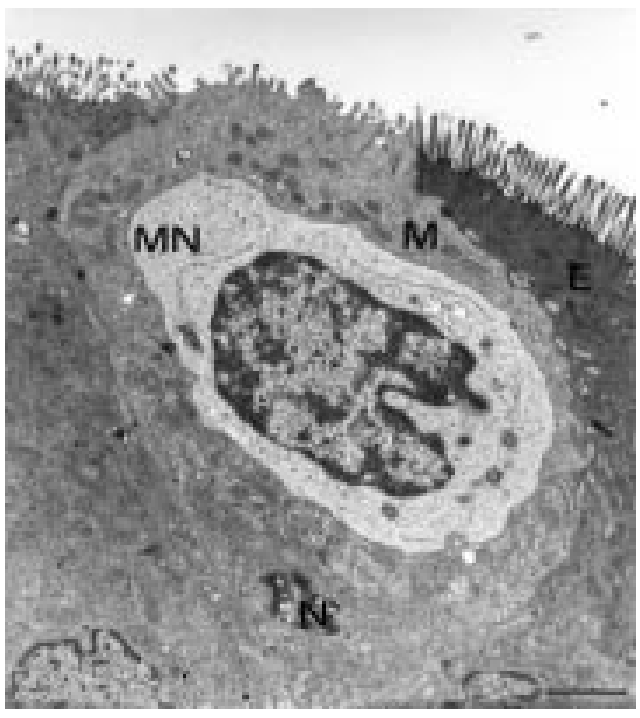

Figure 1 Typical $M$ cell overlying a lymphoid follicle of human appendix embedded in Epon. The surface of the $M$ cell $(M)$ shows microfolds and fewer, shorter microvilli than the adjacent absorptive enterocytes (E). A mononuclear cell in the central hollow (MN) is surrounded by $M$ cell cytoplasm. The cell nucleus $(N)$ is located at the base of the $M$ cell $($ Bar $=0.5 \mu \mathrm{m})$.
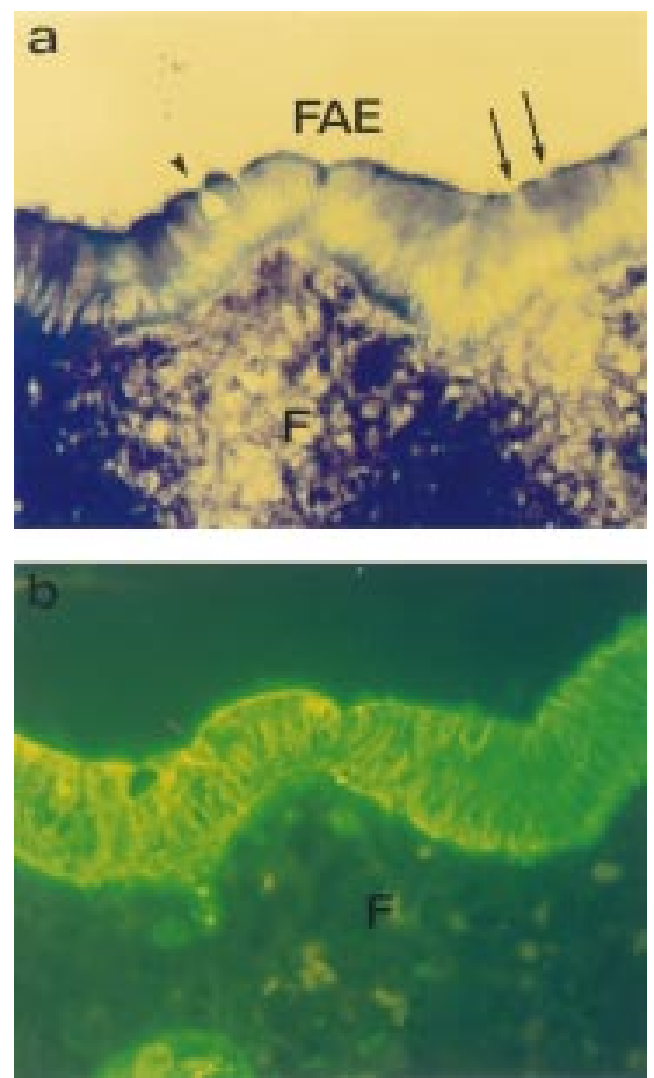

Figure 2 Photomicrograph of frozen sections of FAE from human appendix. The AP reaction is prominent over the FAE of human appendix but is intermittently broken by gaps (arrows) (a). Because of the lack of staining for $A P$, these cells are characterised as $M$ cells. Labelling of the same area with a monoclonal antibody against $C K-20$ (green fluorescence) shows that there is no difference in the staining pattern of $M$ cells and adjacent enterocytes (b). The arrowhead in (a) indicates a goblet cell. Original magnification $\times 400$. F, follicle.

females, nine males; mean age 52 years, range 27-81) undergoing cystectomy because of carcinoma of the urinary bladder. All patients gave written informed consent to participate in the study. The study protocol was approved by the Human Studies Committee of the University of Münster. Macroscopically and microscopically the appendix was not inflamed in any of the patients investigated.

Tissue was taken immediately after resection of the appendix and rinsed with cold Ringer's solution. Small pieces were fixed overnight at $4^{\circ} \mathrm{C}$ in $2.5 \%$ glutaraldehyde (Serva, Heidelberg, Germany). Samples that were taken for cryosections were embedded in OCT (Miles, Elkhart, Indiana, USA), snap frozen, and stored in liquid nitrogen. Cryosections were serially cut at $-25^{\circ} \mathrm{C}$ with a Jung Frigocut N2800 (Leica, Nussloch, Germany) $(5 \mu \mathrm{m})$, fixed in acetone $\left(-20^{\circ} \mathrm{C}\right)$ for 10 minutes, and stored at $-70^{\circ} \mathrm{C}$ until use. For paraffin wax sections, the material was fixed in $10 \%$ formaldehyde for 20 hours at room temperature and embedded in paraffin wax. Sections of $2 \mu \mathrm{m}$ were dewaxed, rehydrated in a series of alcohol, and transferred to phosphate buffered saline (PBS) ( $\mathrm{pH} \mathrm{7.2).} \mathrm{For} \mathrm{morphological} \mathrm{evaluation,}$ the material was stained with haematoxylin (Merck, Darmstadt, Germany). Sections with activated lymphoid follicles and corresponding 

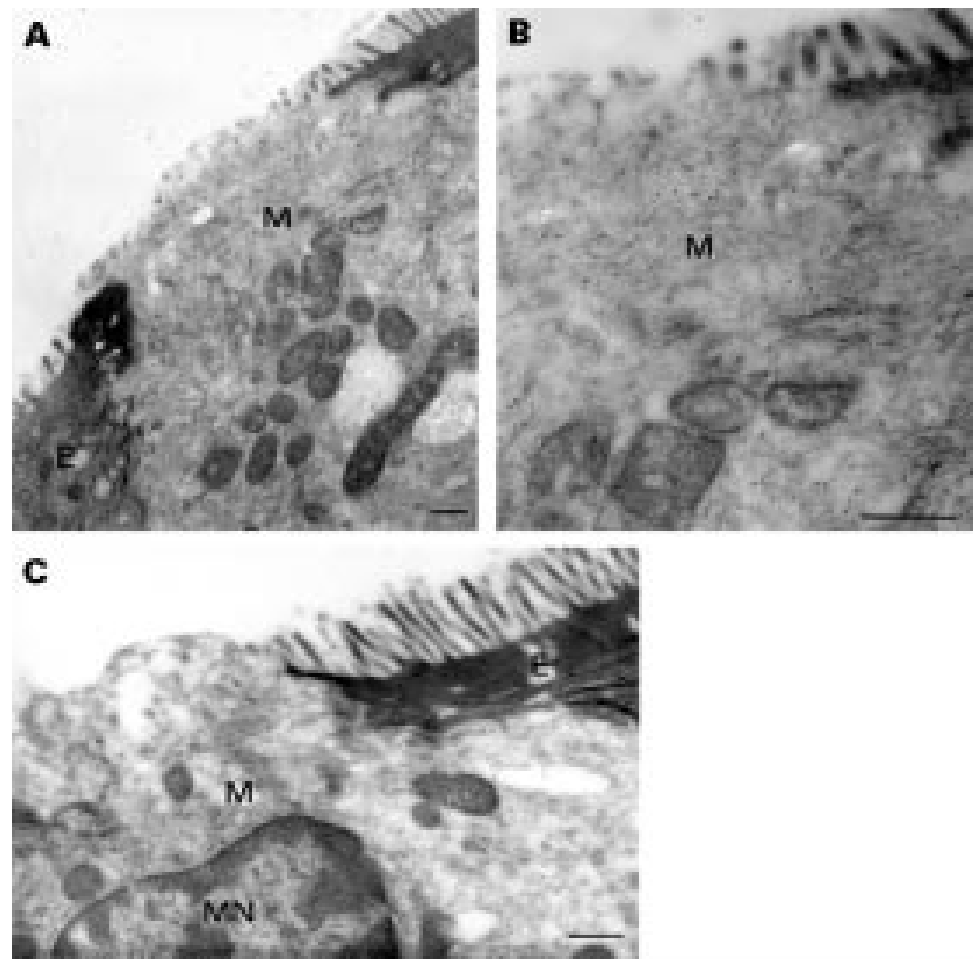

Figure 3 Immunogold labelling for cytokeratin 19 of $M$ cells in the human appendix. Cytokeratin peptide 19 is expressed in the whole cytoplasm of the $M$ cell $(M)$ (A) while it is not in the apical membrane (C), the mononuclear cell (MN) (C), and the mitochondria. The staining of the immunogold labelled antibody is homogeneous and shows the same intensity and distribution as the neighbouring enterocyte (E). The intermediate filaments of the $M$ cell are arranged in meshworks of wavy bundles (B) as is characteristic for intermediate filaments in intestinal epithelium. The terminal web is characterised by a dense packing of mostly non-orientated filaments which are stained by immunogold (Bars $=0.5$ $\mu \mathrm{m})$.

FAE from each patient were selected for immunohistochemistry and immunogold electron microscopy.

$M$ cells were identified during electron microscopy by their characteristic morphological features. For immunohistochemical studies, costaining with a marker for alkaline phosphatase (AP) was used because of the absence of this enzyme in the brush border of $M$ cells. FAE cells with a pocket harbouring lymphoid cells and without AP in the brush border were characterised as $M$ cells.

PRIMARY AND SECONDARY ANTIBODIES

Table 1 presents working dilutions and suppliers of all monoclonal antibodies used for immunohistochemistry and immunogold electron microscopy. Antibodies were purchased from Sigma (Deisenhofen, Germany), Boehringer (Mannheim, Germany), Immunotech (Hamburg, Germany), Progen (Heidelberg, Germany), and Medac (Hamburg, Germany). As secondary antibodies, we used goat antimouse fluorescein isothiocyanate (FITC) or dichlorotriazinyl aminofluorescein (DTAF) labelled antibodies and unconjugated goat antimouse IgG antibodies which were all purchased from Dianova (Hamburg, Germany).

IMMUNOFLUORESCENCE STAINING

Cryosections, approximately $5 \mu \mathrm{m}$ thick, were transferred to PBS ( $\mathrm{pH} 7.2$ ) after fixation with acetone. Paraffin wax sections, approximately 2 $\mu \mathrm{m}$ thick, were dewaxed, rehydrated in a series of alcohol and transferred to PBS ( $\mathrm{pH}$ 7.2). The sections were blocked with $50 \%$ goat serum containing $0.1 \%$ bovine serum albumin (BSA) in PBS for one hour and then incubated with the primary antibody diluted in PBS containing $0.1 \%$ BSA for 60 minutes or overnight at $4^{\circ} \mathrm{C}$ in a moist chamber. Afterwards they were rinsed in PBS three times for 30 minutes, incubated with the second antibody, FITC, DTAF, or unconjugated goat antimouse IgG $1 / 50$ for 1.5 hours at room temperature and rinsed again in PBS. The second antibody was preincubated for 60 minutes with $20 \%$ human $\mathrm{AB}$ serum at room temperature to minimise non-specific binding. In paraffin wax sections, the secondary antibody was developed with a polyclonal mouse APAAP complex (1/100, 60 minutes at room temperature; Dianova, Hamburg, Germany). The sections were enclosed in Moviol-gel (Calbiochem, La Jolla, California, USA) and evaluated using a Zeiss Axiophot fluorescence microscope. Controls were performed either without the first or the second antibody. All controls were negative.

Immunohistochemical demonstration of $\mathrm{M}$ cells was performed by a modification of the method of Owen and Bhalla ${ }^{14}$ based on the absence of a brush border with AP in these cells. Staining for AP was done with nitroblue tetrazolium/5-bromo-4-chloro-3-indolyl phosphate (NBT-BCIP, Sigma, Deisenhofen, Germany). After staining with the primary antibody or after hemalam staining, frozen sections were stained with NBT $(0.03 \%)$ plus BCIP $(0.015 \%)$ (Life Technologies, Eggenstein, Germany) soluted in Tris buffer ( $\mathrm{pH} 9.5)$ for one hour, rinsed in PBS ( $\mathrm{pH}$ 7.2) for 30 minutes, and enclosed in Moviol gel.

TRANSMISSION ELECTRON MICROSCOPY

Tissue specimens of human non-inflamed appendix were washed with cold PBS, cut into small pieces, and fixed immediately after appendectomy in $2.5 \%$ glutaraldehyde in phosphate buffer $\mathrm{pH} 7.2$ (containing $0.9 \%$

Table 2 Localisation of intermediate filaments in $M$ cells and enterocytes of the human appendix

\begin{tabular}{lllll}
\hline \multicolumn{5}{c}{ Enterocytes } \\
\cline { 3 - 5 } & M cells & FAE & Villus & Crypt \\
\hline Cytokeratin 1 & $-/ 0$ & $-/ 0$ & $-/ 0$ & $-/ 0$ \\
Cytokeratin 2 & $-/ 0$ & $-/ 0$ & $-/ 0$ & $-/ 0$ \\
Cytokeratin 3 & $-/ 0$ & $-/ 0$ & $-/ 0$ & $-/ 0$ \\
Cytokeratin 4 & $-/ 0$ & $-/ 0$ & $-/ 0$ & $-/ 0$ \\
Cytokeratin 5 & $-/ 0$ & $-/ 0$ & $-/ 0$ & $-/ 0$ \\
Cytokeratin 6 & $-/ 0$ & $-/ 0$ & $-/ 0$ & $-/ 0$ \\
Cytokeratin 7 & $-/ 0$ & $-/ 0$ & $-/ 0$ & $-/ 0$ \\
Cytokeratin 8 & $+++/ 2$ & $+++/ 2$ & $+++/ 2$ & $+/ 2$ \\
Cytokeratin 10 & $-/ 0$ & $-/ 0$ & $-/ 0$ & $-/ 0$ \\
Cytokeratin 11 & $-/ 0$ & $-/ 0$ & $-/ 0$ & $-/ 0$ \\
Cytokeratin 13 & $-/ 0$ & $-/ 0$ & $-/ 0$ & $-/ 0$ \\
Cytokeratin 14 & $-/ 0$ & $-/ 0$ & $-/ 0$ & $-/ 0$ \\
Cytokeratin 15 & $-/ 0$ & $-/ 0$ & $-/ 0$ & $-/ 0$ \\
Cytokeratin 16 & $-/ 0$ & $-/ 0$ & $-/ 0$ & $-/ 0$ \\
Cytokeratin 17 & $-/ 0$ & $-/ 0$ & $-/ 0$ & $-/ 0$ \\
Cytokeratin 18 & $+++/ 4$ & $+++/ 4$ & $+++/ 4$ & $++/ 2$ \\
Cytokeratin 19 & $+++/ 2$ & $+++/ 2$ & $+++/ 2$ & $++/ 2$ \\
Cytokeratin 20 & $+++/ 4$ & $+++/ 4$ & $+++/ 4$ & $(+) / 3$ \\
Vimentin & $-/ 0$ & $-/ 0$ & $-/ 0$ & $-/ 0$ \\
Desmin & $-/ 0$ & $-/ 0$ & $-/ 0$ & $-/ 0$ \\
\hline Percentage o & & & &
\end{tabular}

Percentage of positive structures: $0 \%,-; 0-20 \%,(+) ; 20-40 \%$, +; 40-60\%, ++; 60-100\%, +++.

Staining intensity: 0 , no immunoreactivity; 1 , weakly stained; 2 , medium staining; 3 , strong staining; 4 , very strong staining. 

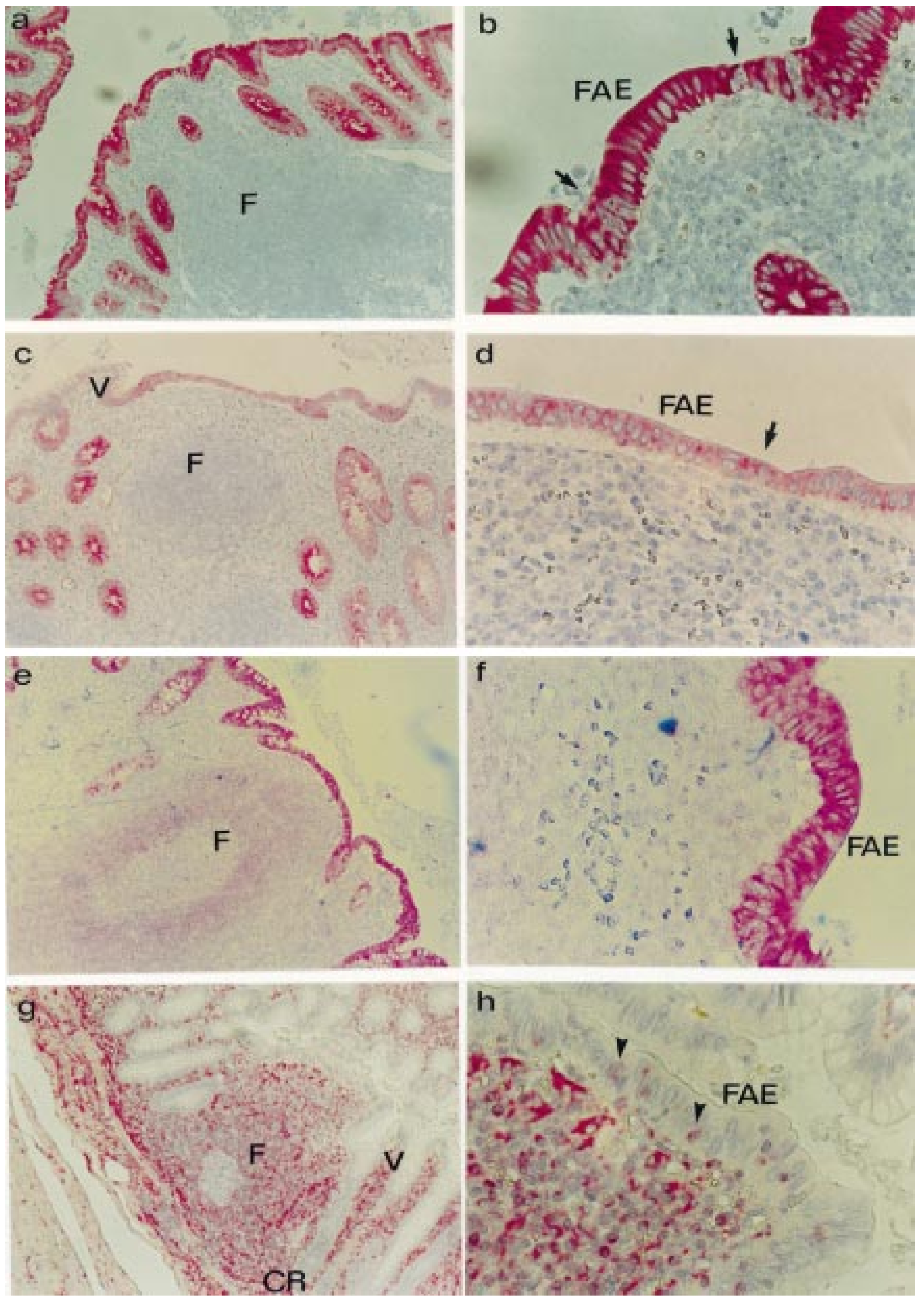

Figure 4 Photomicrographs of frozen sections showing the typical organisation of a Peyer's patch in the human appendix with the dome region of the lymphoid follicle including FAE (a). The FAE is characterised by missing goblet cells. The sections are stained with monoclonal antibodies for different cytokeratins and vimentin. Monoclonal antibodies to $C K-18(a, b)$ and $C K-19(c, d)$ stained the FAE with the same intensity and no difference between the cells. $M$ cells could not be visualised by light microscopy, but can be suspected in the FAE with pockets of mononuclear cells in the epithelial membrane (arrows) or by staining for AP. Monoclonal antibodies against CK-8 stained all cells in the FAE (e,f). The intracellular distribution of CK-8 is somewhat irregular with predominant staining of the subapical and perinuclear part of the cells. Antibodies against vimentin are strongly stained in the mesenchyme of the dome region, but there is no distribution of vimentin in the $F A E(g, h)$. Intraepithelial lymphocytes are strongly stained by monoclonal antibodies against vimentin (arrowheads) (h). $a, c, e, g, \times 100 ; b, d, f, h, \times 400$. CR, crypt; V, villus; $F$, follicle. 

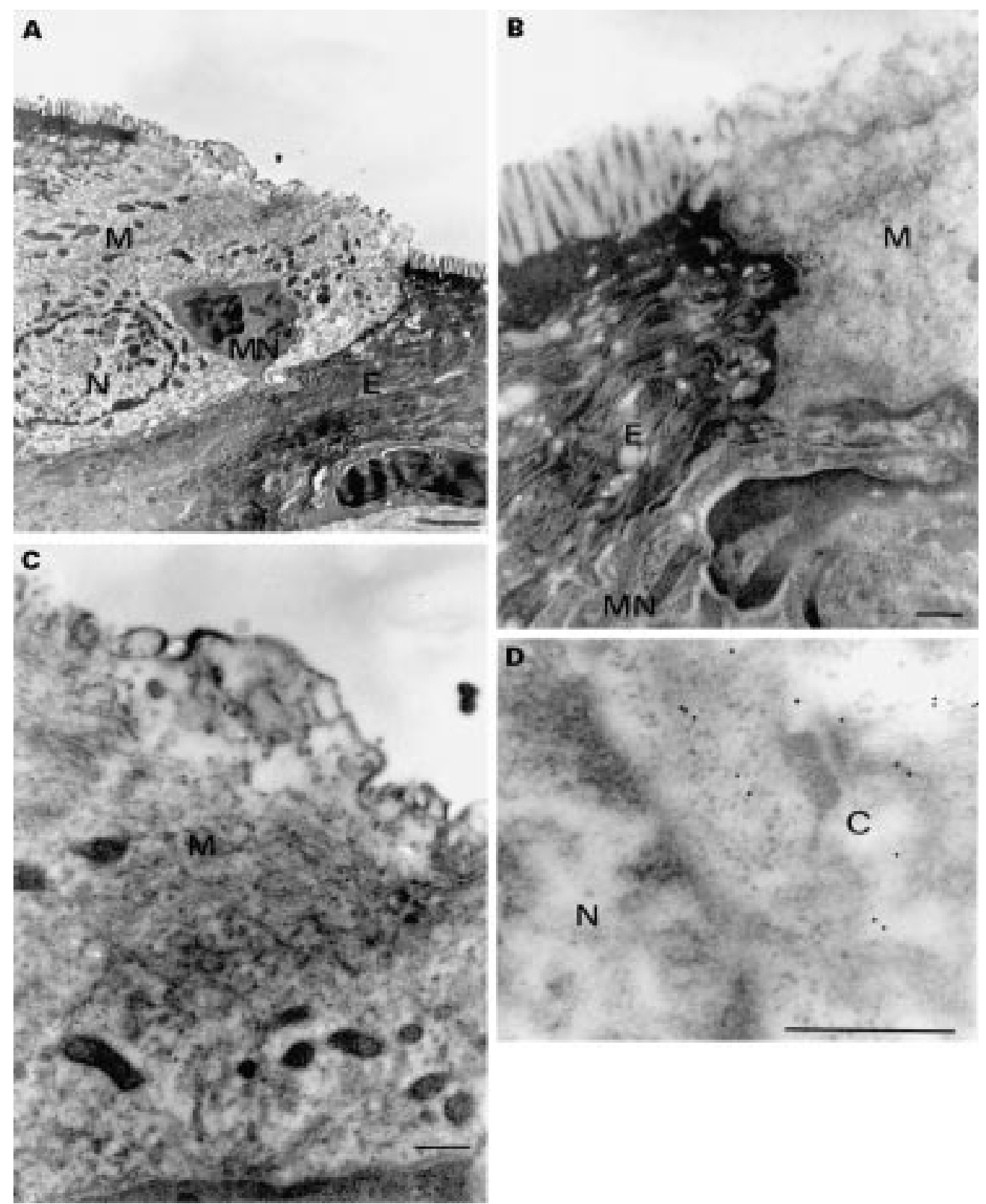

Figure 5 Human appendix. (A) $M$ cell (M) with two adjacent enterocytes (E). LR-White embedded tissue labelled with immunogold anticytokeratin 18 monoclonal antibody. Typical microfolds instead of regular microvilli and a mononuclear cell $(M N)$ in the cytoplasm. Homogeneous labelling of $C K-18$ by gold particles $(B, C)$ with no difference between the $M$ cell and the adjacent enterocyte. Immunogold labelling is absent in the apical membrane of both cells $(B, C)$, the mononuclear cell $(A, B)$, and the nucleus $(D)$. The terminal web is more intensively stained than the middle part of the $M$ cell. $N$, nucleus; $C$, cytoplasm. (Bars: $A=2 \mu \mathrm{m} ; B, C, D=0.5 \mu \mathrm{m}$ ).

potassium dihydrogen phosphate and $1.2 \%$ disodium hydrogen phosphate; Merck, Darmstadt, Germany). After fixation, the tissue was washed in buffer, dehydrated, and embedded in Epon (Serva, Heidelberg, Germany). Semithin sections $(1 \mu \mathrm{m})$ were mounted on glass slides and stained with toluidine blue to select areas of lymphoid follicle with FAE where $M$ cells were suspected. Ultra-thin sections of the selected FAE were cut with diamond knives on an ultramicrotome and mounted on uncoated mesh grids. For morphological studies, the sections were contrasted with uranyl acetate and lead citrate and examined under a Philips CM 10 electron microscope by one of the authors (TK).
For immunogold electron microscopy, we used a modified method developed by Roth. ${ }^{19}$ Tissue was fixed in $0.5 \%$ glutaraldehyde and $4 \%$ paraformaldehyde for four hours. After primary fixation, the tissue blocks were embedded in LR-White (London Resign Co., Hampshire, UK) at $4^{\circ} \mathrm{C}$. Polymerisation was performed at $56^{\circ} \mathrm{C}$ overnight. Tissue blocks were cut as described above. Antibody labelling of the mesh grids and processing for electron microscopy were done at room temperature by the following procedure. Sections were incubated with $4 \%$ chicken egg albumin (Sigma), rinsed in buffer, and then incubated with the primary antibody (for concentrations see table 1) for 16 hours at room temperature in a moist 
chamber. After careful washing with PBS, the sections were treated with protein A gold complex (12 nm, Sigma, Deisenhofen, Germany) for three to six hours. Sections were then contrasted with uranyl acetate and lead citrate and examined as described earlier.

\section{Results}

CHARACTERISATION OF M CELLS

In electron microscopic sections embedded in Epon or LR-White, we identified $M$ cells by their characteristic morphological features. Cells with microfolds instead of regular microvilli as compared with the adjacent cells, with numerous vesicles in their apical cytoplasm and a basolateral pocket harbouring lymphocytes, were characterised as $\mathrm{M}$ cells (fig 1). $M$ cells of the appendix usually presented with microfolds, while regular or irregular appearing microvilli were seen only rarely in $\mathrm{M}$ cells.

By light microscopy, characterisation of cells in the FAE as $M$ cells was more difficult as their distinct morphological features cannot be detected. Therefore, we used a modification of the method described by Owen and Bhalla ${ }^{14}$ who demonstrated that $M$ cells are characterised by a lack of staining for AP in the brush border as compared with adjacent enterocytes. We used the substrate complex NBT-BCIP for staining AP, since the brush border of epithelial cells in the appendix contains less AP than enterocytes of the ileum and, therefore, common fast red staining was not sensitive enough. In the human appendix, NBT-BCIP could very sensitively detect AP in the brush border of enterocytes and missed staining $M$ cells in unstained frozen sections (fig 2). Therefore, we identified cells covering the lymphoid follicle as $M$ cells if they showed a lack of the staining for $\mathrm{AP}$ and harboured lymphocytes in their basolateral pocket. Costaining with various antibodies made it possible to characterise the staining pattern in $\mathrm{M}$ cells (fig 2). Alcian blue staining permitted distinction from goblet cells due to lack of mucin (data not shown).

CYTOKERATINS IN M CELLS

Cytokeratin expression in $\mathrm{M}$ cells of the human appendix was assessed by immunohistochemistry of cryosections and by immunogold electron microscopy. We used different monoclonal antibodies for detection of the composition of intermediate filaments (table 1). For cytokeratins which seemed to be of interest in $M$ cells, we used different clones of monoclonal antibodies as there are reports of distinct differences in binding specificity between different clones of, for example, monoclonal antibodies against cytokeratin peptide 8 in rat $\mathrm{M}$ cells. ${ }^{17}$

Intermediate filaments in the $M$ cells are arranged in a meshwork of fine fibrils. The apical area of $M$ cells as well as enterocytes is totally free from intermediate filaments. The terminal web shows a relatively dense meshwork of mostly non-bundled intermediate sized filaments (fig 3).

Cytokeratin 1, CK-2, CK-3, CK-4, CK-5, CK-6, CK-7, CK-10, CK-11, CK-13, CK-14, CK-16, and CK-17 could not be detected on frozen sections of the follicle associated epithe- lium and epithelial villi of the appendix (table 2). For all antibodies used, positive controls were obtained in well characterised tissues (data not shown).

Antibodies against cytokeratins 8, 18, 19, and 20 labelled all epithelial villi and the FAE covering the dome homogeneously and with equal intensity; this could be demonstrated in APAAP labelled paraffin wax sections (fig 4) and fluorescence labelled frozen sections (fig 2 ). None of the antibodies against these cytokeratins distinguished between epithelial cells of the FAE and the surrounding villi and reacted with comparable intensity with all intestinal epithelial cells (table 2). Crypt cells were less stained by monoclonal antibodies against CK-18 and CK-19 compared with FAE cells or epithelial villi (fig 4 , table 2). CK-8 and CK-20 were only expressed in some crypt cells. Monoclonal antibodies against CK-18 and CK-20 revealed the strongest staining pattern in the FAE. $M$ cells, which were identified by their failure to stain for AP in the brush border, showed the same staining for cytokeratin monoclonal antibodies as adjacent enterocytes (fig 2). Even at very low concentrations for the antibodies against the different cytokeratins, we could not determine any difference in the staining pattern between different cells in the FAE. The nucleus remained unstained by all antibodies used but the perinuclear region was strongly stained. The subcellular distribution was somewhat different between individual cytokeratins. CK-20 and CK-18 were more intensively stained in the subapical and basal parts of the FAE cells while monoclonal antibodies against CK-19 stained cells more homogeneously. CK-8 was predominantly distributed in the perinuclear region. Between different clones for monoclonal antibodies against cytokeratins $8,18,19$, and 20 (see table 1 ), we could not find any differences in the intensity or quality of the staining of FAE and epithelial villi. Neither were there any differences concerning the staining pattern in appendices from different patients of varying age.

None of the antibodies used in our study (table 1) exhibited any distinct staining pattern, as, for example, the recognition of single cells in the FAE of the dome.

As shown by immunogold electron microscopy, labelling with cytokeratin antibodies against CK-18 in human enterocytes of the FAE as well as of the adjacent villi showed an equal distribution within the cytoplasm that excluded the brush border and the nucleus (fig 5). Adjacent $M$ cells showed the same distribution and intensity of immunogold staining in the cytoplasm and lack of staining of the apical, microfolded membrane. The nucleus as well as mononuclear cells remained unstained. Staining for CK-18 in $M$ cells excluded the apical, microfolded membrane and showed a somewhat stronger reaction subapically in the terminal web and in basolateral parts than in the mid portion of the cell. The ultrastructural distribution of CK-19 was similar to that of CK-18 (fig 3). However, the staining for CK-19 showed a lower intensity compared with CK-18 and the cellular distribution was a 
little more homogeneous. The immunogold labelled antibodies stained along the cytokeratin filaments as shown in fig 3 . We could not determine any distinct difference in the intensity of staining for CK-19 between $M$ cells and adjacent enterocytes. Staining for CK-19 was uniformly distributed between $M$ cells and neighbouring enterocytes.

VIMENTIN AND DESMIN

Using a monoclonal antivimentin antibody on immunolabelled frozen and paraffin wax sections, we could not detect any vimentin expression on epithelial cells of the FAE or the adjacent villi. In contrast, there was strong staining in the subepithelial dome area. In the epithelial layer some intraepithelial lymphocytes were stained (fig 4). The desmin antibody did not stain any of the epithelial cells of the FAE of the appendix, whereas smooth muscle fibres of blood vessels and the muscularis propria were intensely stained (data not shown). Neither of these two antibodies exhibited any distinct staining pattern of single cells in the FAE.

\section{Discussion}

Our study shows that $M$ cells from human intestinal FAE express intermediate filaments which closely resemble those of intestinal epithelial cells. The composition of cytokeratins in the FAE was homogeneous and not different between $M$ cells and adjacent enterocytes. Vimentin and desmin, components of either mesenchymal or myogenic tissue, and other cytokeratins are not expressed in human $\mathrm{M}$ cells.

Different human cells and tissues are characterised by a specific composition of intermediate filaments. Cytokeratins 8, 18, 19, and 20 are arranged in pairs and are characteristic of intestinal epithelial cells. ${ }^{18}{ }^{20}$ Intermediate filaments are ubiquitous components of the cytoskeleton, but their physiological role has not yet been clearly established. It is supposed that they have a function in mechanical coordination of the cytoskeleton. ${ }^{21}$ The differential expression of certain cytokeratins seems to be closely linked with specific programmes of differentiation. ${ }^{20} 22$

Several studies in different species have shown that cytoskeletal components of $\mathrm{M}$ cells partially differ from those of adjacent enterocytes. Vimentin, a marker commonly detected in mesenchymal cells, is coexpressed with cytokeratins in rabbit $M$ cells. It has been shown to be a sensitive marker of these cells, because of its absence in adjacent enterocytes. ${ }^{16}{ }^{23}$ Intermediate filaments from rat $M$ cells differ from absorptive enterocytes by strong staining for a specific monoclonal antibody clone against $\mathrm{CK}-8 .{ }^{17}$ Cytokeratin 18 , a cytoskeletal component of intestinal epithelial cells, is strongly expressed in porcine $M$ cells. ${ }^{15}$ Villin, a cytoskeletal brush border protein, has an unusual distribution pattern in the cytosol of $\mathrm{M}$ cells from Balb/c mice. ${ }^{26}$ Thus, there are several $M$ cell markers which have been shown to be highly species specific. At present the reason for this is not known.
Up to now, very few studies on human intestinal $M$ cells have been reported. One obvious reason for this is the difficulty of finding lymphoid follicles with associated epithelium and $M$ cells in the human intestine. As plenty of lymphoid follicles occur in the human appendix, however, we decided to use uninflamed appendix as a model for morphological studies of human intestinal M cells. Our study shows that the composition of intermediate filaments in human $\mathrm{M}$ cells is no different from that in enterocytes. As basic intermediate filaments, we determined different cytokeratins, especially cytokeratins $8,18,19$, and 20 , which are believed to be selectively expressed in intestinal enterocytes. ${ }^{18}{ }^{20}$ Using immunohistochemistry and immunogold electron microscopy techniques we were able to show that all of these cytokeratins are expressed in human $M$ cells as well. The subcellular distribution and quantity of staining for CK-18 and CK-19 is no different between $M$ cells and enterocytes as shown by immunogold electron microscopy (figs 3 and 5). The nucleus of the $M$ cells remained unstained and the brush border was less stained by antibodies against CK-18 and CK-19 which is the typical distribution in epithelial cells of the intestine. ${ }^{24}{ }^{25}$ The rest of the cytoplasm was stained with equal intensity in $M$ cells and enterocytes for monoclonal antibodies against CK-19. CK-18 was predominantly distributed in the subapical and basal parts of the cell. Frozen and paraffin wax sections were stained with fluorescence or peroxidase labelled anticytokeratin monoclonal antibodies (CK-8, CK-18, CK-19, and CK20) and costained with NBT-BCIP to detect $\mathrm{AP}$ in the brush border. All of these antibodies stained the cells of the FAE with the same intensity, which indicated that the expression of intermediate filaments in $M$ cells and neighbouring enterocytes is homogeneous. We could not detect any differences in the staining pattern of $\mathrm{M}$ cells, characteristically lacking AP activity in their apical membrane, and neighbouring enterocytes. Even at high dilutions of the antibodies used, we could see no differences in the staining pattern. Antibodies against various other cytokeratin peptides did not show any staining in $M$ cells, adjacent enterocytes, or epithelial villi (table 2). As the distribution and composition of different cytokeratins is highly specific for certain cell types, the presence of CK-8, CK-18, CK-19, and CK-20 in $M$ cells with the same distribution as in adjacent absorptive cells and the absence of desmin and vimentin supports the hypothesis of an intestinal epithelial origin of human $M$ cells.

Because of the different composition of cytoskeleton components in $\mathrm{M}$ cells and enterocytes in some animal systems, it was suggested that the specialised function of $M$ cells might be mirrored by the expression of distinct intermediate filaments. Logically, it might now be argued that similarities in the cytoskeleton are evidence against functional differences between $M$ cells and enterocytes in humans. This conclusion, however, is too premature. To our knowledge, the whole 
complexity of intermediate filaments in human intestinal epithelial cells is not yet fully elucidated. It is quite possible that there are actually other unknown components of the cytoskeleton that are different between $M$ cells and enterocytes. Several animal studies investigating the glycocalix and brush border enzymes of $M$ cells have shown that there are various differences in the ultrastructural morphology of the apical part of $M$ cells compared with enterocytes (for review, see Neutra $e a^{42}$ ). As the physiological role of intermediate filaments is not clearly understood, ${ }^{27}{ }^{28}$ it is not known whether the cytoskeletal components examined in our study are really correlated with the functional properties of $M$ cells.

As others have shown in animal studies, ${ }^{15} 34$ we were able to show that human intestinal $M$ cells are of epithelial and not mesenchymal origin. There are essentially two hypotheses with respect to the differentiation pathway. Some authors postulate that $M$ cells arise from those absorptive cells overlying the domes of Peyer's patches, ${ }^{8}$ 29-31 43 probably by induction from intraepithelial lymphocytes. ${ }^{30-32}$ Other groups suggest that $M$ cells have the same origin as other differentiated intestinal epithelial cells and derive directly from stem cells in the surrounding crypts. ${ }^{33}$ Our data do not provide definitive evidence in favour of or against either hypothesis, but the results presented suggest that at least in humans the development into $M$ cells occurs at a late step in differentiation. As only the apical surface of human $M$ cells seems to be altered while the intermediate filaments are the same as those found in enterocytes, it is unlikely that the differentiation occurs at the stem cell level in the crypts. It is more likely that $M$ cells develop from fully differentiated enterocytes induced, perhaps, by soluble factors. The hypothesis of $M$ cell differentiation by the subepithelial immune environment is further supported by recent studies of human intestinal cell lines (Caco-2) which converted into " $M$ cell like cells" on coculture with cells from Peyer's patches. ${ }^{35}$ As several studies have shown that the apical plasma membrane of $M$ cells differs considerably from that of enterocytes, ${ }^{36-41}$ it is conceivable that human enterocytes in the presence of an immunological environment develop into $M$ cells, changing their surface to allow adherence and phagocytosis of antigens while the intermediate filament cytoskeleton remains unchanged.

Until now, most morphological and functional $\mathrm{M}$ cell studies have been done in animals and have not been confirmed in humans. Data presented in this study show that results obtained by the investigation of animal tissues are not always compatible with those derived from human studies. More investigations in man are therefore necessary to elaborate further the concepts of the morphology and function of human intestinal $M$ cells.

The authors thank Mrs Birgit Kunk for her excellent technical assistance in electron microscopy. Human appendices were kindly provided by Prof. Dr L Hertle, Department of Urology of the University of Münster. This study was supported by a grant
from the Interdisciplinary Center for Clinical Research (IKF, D4).

1 Owen RL, Jones AL. Epithelial cell specialization within human Peyer's patches: an ultrastructural study of human Peyer's patches: an ultrastructural study of 203.

2 Bockman DE, Cooper MD. Early lymphoepithelial relationships in human appendix. A combined light- and electronmicroscopic study. Gastroenterology 1975;68:1160-8.

3 Neutra MR, Phillips TL, Mayer EL, Fishkind DJ. Transport of membrane-bound macromolecules by $M$-cells in follicle associated epithelium of rabbit Peyer's patch. Cell Tissue Res 1987;247:537-46.

4 Wolf JL, Bye WA. The membraneous epithelial (M) cell and the mucosal immune system. Annu Rev Med 1984;35:95112.

5 Bockman DE, Stevens W. Gut associated lymphoepithelial tissue: bidirectional transport of tracer by specialized epithelial cells associated with lymphoid follicles. $\mathcal{f}$ Reticuloendothel Soc 1977;21:245-54.

6 Jepson MA, Simmons NL, Savidge TC, James PS, Hirst BH. Selective binding and transcytosis of latex microspheres by rabbit intestinal $\mathrm{m}$ cells. Cell Tissue Res spheres by rabbit

7 Trier JS. Structure and function of M cells. Gastroenterol Clin North Am 1991;20:531-47.

8 Owen RL. And now pathophysiology of M-cells-good news and bad news from Peyer's patches. Gastroenterology 1983;85:468-70.

9 Wolf JL, Kauffman RS, Finberg R, Dambrauskas R, Fields BN, Trier JS. Determinants of reovirus interaction with the intestinal $\mathrm{M}$ cells and absorptive cells of murine intestine. Gastroenterology 1983;85:291-300.

10 Pappo J, Steger H, Owen R. Differential adherence of epithelium overlying gut-associated lymphoid tissue. $L a b$ Invest 1988;58:692-7.

11 Jones BD, Ghori N, Falkow S. Salmonella typhimurium initiates murine infection by penetration and destroying the
specialized epithelial $M$ cells of the Peyer's patches. $\mathcal{F}$ Exp Med 1994;180:15-23.

12 Sass W, Dreyer HP, Seifert J. Rapid insorption of small particles in the gut. Am $\mathcal{f}$ Gastroenterol 1990;85:255-60.

13 Owen RL, Nemanic P. Antigen processing structures of the Owen RL, Nemanic P. Antigen processing structures of the
mammalian intestinal tract: an SEM study of lymphoepithelial organs. In: Becker RP, Johari O, eds. Scanning electron microscopy. 1978;11:367-78.

14 Owen RL, Bhalla DK. Cytochemical analysis of alkaline phosphatase and esterase activities and of lectin-binding and anionic sites in rat and mouse Peyer's patch $M$ cells. Am f Anat 1983;168:199-212.

15 Gebert A, Rothkötter HJ, Pabst R. Cytokeratin 18 is an M-cell marker in porcine Peyer's patches. Cell Tissue Res 1994;276:213-21.

16 Gebert A, Hach G, Bartels H. Co-localization of vimentin and cytokeratins in M-cells of rabbit gut-associated
lymphoid tissue (GALT). Cell Tissue Res 1992;269:331-40.

17 Rautenberg K, Cichon C, Heyer G, Demel M, Schmidt MA. Immunocytoch AA. Immunocytochemical characterization of the follicleassociated epithelium of Peyer's patches: anticytokeratin-8 antibody (clone 4.1.18) as a molecular

18 Moll R, Franke WW, Schiller D. The catalog of human cytokeratins: patterns of expression in normal epithelia, tumors and cultured cells. Cell 1982;31:11-24.

19 Roth J. The protein A-gold (pAg) technique: a qualitative and quantitative approach for antigen localization on thin sections. In: Bullock GR, Petrusz, eds. Techniques in immunocytochemistry. Vol 1. New York: Academic Press, 1982:108-33.

20 Moll R, Löwe A, Laufer J, Franke WW. Cytokeratin 20 in human carcinomas. A new histodiagnostic marker detected by monoclonal antibodies. Am f Pathol 1992;140:427-47.

21 Lazarides E. Intermediate filaments as mechanical integrators of cellular space. Nature 1980;283:249-56.

22 Steinert PM, Parry DAD. Intermediate filaments: conformity and diversity of expression and structure. Annu Rev Cell Biol 1990;1:41-65.

23 Jepson MA, Mason CM, Benett MK, Simmons NL, Hirst BH. Co-expression of vimentin and cytokeratins in M cells of rabbit intestinal lymphoid follicle-associated epithelium. of rabbit intestinal lymphoid

Histochem f 1992;24:33-9.
24 Franke WW, Schmidt E, Osborn M, Weber K. Different intermediate sized filaments distinguished by immunofluorescence microscopy. Proc Natl Acad Sci USA 1978;75: 5034-8

25 Mooseker MS. Organization, chemistry, and assembly of the cytoskeletal apparatus of the intestinal brush border. Annu Rev Cell Biol 1985;1:209-41.

26 Kerneis S, Bogdanova, Colucci-Guyon E, Kraehenbuhl, Pringault E. Cytosolic distribution of villin in $\mathrm{M}$ cells from mouse Peyer's patches with the absence of a brush border. Gastroenterology 1996;110:515-21.

27 Stewart M. Intermediate filaments: structure, assembly and molecular interactions. Curr Opin Cell Biol 1990;2:91-100.

28 Steinert PM, Roop DR. Molecular and cellular biology of intermediate filaments. Annu Rev Biochem 1988;57:593625.

29 Bhalla DK, Owen RL. Cell renewal and migration in lymphoid follicles of Peyer's patches and cecum - an autoradiographic study in mice. Gastroenterology 1982;82:232-42.

30 Smith MW, Peacock MA. Lymphocyte induced formation of antigen transporting " $M$ " cell distribution in follicle 
associated epithelium of mouse Peyer's patch. Am $\mathfrak{f}$ Anat 1980;159:167-75.

31 Smith MW, Peacock MA. Microvillus growth and M-cell formation in mouse Peyer's patch follicle-associated epithelial tissue. Exp Physiol 1992; 77:389-92.

32 Bockman DE. Functional histology of appendix. Arch Histo fpn 1983;46:271-92.

33 Sicinsky P, Rowinsky J, Warchol JB, Bem W. Morphometric evidence against lymphocyte-induced differentiation of $M$ cells from absorptive cells in mouse Peyer's patches. Gastroenterology 1986;90:609-16.

34 Bye WA, Allan CH, Trier JS. Structure, distribution, and origin of M cells in Peyer's patches of mouse ileum. Gastroenterology 1984;86:789-801.

35 Kernéis S, Bogdanova A, Kraehenbuhl JP, et al. Conversion by Peyer's patch lymphocytes of human enterocytes into $M$ cells that transport bacteria. Science 1997;277:949-52.

36 Giannasca PJ, Giannasca KT, Falk P, Gordon JI, Neutra MR. Regional differences in glycoconjugates of intestinal $\mathrm{M}$ cells in mice: potential targets for mucosal vaccines. $A m$ I Physiol 1994;267:G1108-21.

37 Neutra MR, Phillips TL, Mayer EL, Fishkind DJ. Transport of membrane-bound macromolecules by $M$ cells in follicle- associated epithelium of rabbit Peyer's patch. Cell Tissue Res 1987;247:537-46.

38 Gebert A, Hach G. Differential binding of lectins to $M$ cells and enterocytes in the rabbit cecum. Gastroenterology 1993; 105:1350-61

39 Neutra MR, Frey A, Kraehenbuhl J-P. Epithelial M cells: gateways for mucosal infection and immunization. Cell 1996;86:345-8

40 Wolf JL, Rubin DH, Finberg R, Kauffman RS, Sharpe AH, Trier JS, Fields N. Intestinal M cells: a pathway for entry of reovirus into the host. Science 1981;212:71-2.

41 Inman LR, Cantey JR. Specific adherence of Escherichia coli (strain RDEC-1) to membranous $(\mathrm{M})$ cells of the Peyer's patch in Escherichia coli diarrhea in the rabbit. 7 Clin Invest 1983;71:1-8.

42 Neutra MR, Pringault E, Kraehenbuhl JP. Antigensampling across epithelial barriers and induction of 1996;14: $275-300$.

43 Savidge TC, Smith MW. Evidence that membranous cell genesis is immunoregulated. In: Mestecky J, ed. Advances in mucosal immunology. New York: Plenum Press, 1995:239- 